\title{
The Effect of Irradiance Related Temperature on Microalgae Growth in a Tubular Photo Bioreactor for Cleaner Energy
}

\author{
Ujjwal K. Deb1", M. Shahriar², Joy Bhowmik ${ }^{3}$, M. K. H. Chowdury ${ }^{1}$ \\ ${ }^{1}$ Department of Mathematics, Chittagong University of Engineering \& Technology, Chittagong, Bangladesh \\ ${ }^{2}$ Department of Mechanical Engineering, Chittagong University of Engineering \& Technology, Chittagong, Bangladesh \\ ${ }^{3}$ Center for Sustainable Development, University of Liberal Arts Bangladesh, Dhaka, Bangladesh \\ Email: ukdeb03@gmail.com, tanim0907@gmail.com joy.bhowmik@ulab.edu.bd, hhimadrii@gmail_com
}

How to cite this paper: Deb, U.K., Shahriar, M., Bhowmik, J. and Chowdury, M.K.H. (2017) The Effect of Irradiance Related Temperature on Microalgae Growth in a Tubular Photo Bioreactor for Cleaner Energy. American Journal of Computational Mathematics, 7, 371-384.

https://doi.org/10.4236/ajcm.2017.73026

Received: August 1, 2017

Accepted: September 25, 2017

Published: September 28, 2017

Copyright $\odot 2017$ by authors and Scientific Research Publishing Inc. This work is licensed under the Creative Commons Attribution International License (CC BY 4.0).

http://creativecommons.org/licenses/by/4.0/

\begin{abstract}
In microalgae based biofuel technology, the light is one of the important factors for the proper growth of microalgae cells as microalgae is a photosynthetic microorganism. For a large scale outdoor culture the irradiance of sunlight and associated temperature is also need to consider. In this study aims to present computational model of microalgae growth taking effect of solar irradiance and corresponding temperature in a tubular photo bioreactor for an outdoor culture system. We consider the transient behavior of temperature inside the photo bioreactor for a microalgae culture. The optimum range of temperature for outdoor cultivation of microalgae is about $22^{\circ} \mathrm{C}-27^{\circ} \mathrm{C}$ and out of this range the microalgae cell growth inhibits. Many correlations have already been established to investigate the algal productivity based on the dynamic conditions of temperature in case of full scale outdoor cultivation. However, none of them are validated yet numerically considering the model as a function of weather conditions, operational behavior and design criteria. A tubular photobioreactor (PBR) with length $20.5 \mathrm{~m}$ and radius $0.05 \mathrm{~m}$ has taken account as a simulation model. The PBR is horizontally placed as temperature variations can be observed with greater accuracy. As the solar irradiance varies at any geographic latitude for a year and so thus temperature, equations and parameters are established relating the irradiance with the temperature to simulate the effect. We observed some significant effects of temperature on the growth of microalgae. Moreover, for the maximum growth of the cells we should control the surrounding temperature.
\end{abstract}

\section{Keywords}

Microalgae, Biofuel, Photo Bioreactor, Solar Irradiance, Temperature, Simulation 


\section{Introduction}

With the advent of the $21^{\text {st }}$ century, the world has begun to face with two major crises: one is the depletion of fossil fuel due to increasing demand and the other one is consequent dependency on the fossil fuel exporting countries. In the recent world, rapid industrialization and motorization has led the people to a steep rise for the demand of petro fuel. The burning of the fossil fuel causes the environmental hazards like: climate change, increased concentrations of GHG, depletion of ozone layer etc. So now it is a prime concern for the scientist and researchers to find out a carbon neutral droplet that would save the world from probable degradation of the environment [1] [2]. To overcome this problem plant based biofuels has become a potential resource which is carbon neutral and can replace petro based fuel. Even though biofuel production from crops still costly compared to fossil fuel as they require large amount of arable land [3]. So a new feedstock is required to mitigate the global demand and produce the biofuel commercially. Among the biofuel sources, some of the algae species have shown best potential for biofuel production. So Microalgae biofuel has received a lot of attention of researchers and engineers since the last few decades as an alternative feedstock [4].

Microalgae are unicellular photosynthetic microorganisms that utilize atmospheric carbon dioxide and sunlight to produce sugars which support biomass growth. Some species of algae yield high oil content which is 100 times faster than any terrestrial plant [5]. Technology, using and producing microalgae has been known for fifty years [4]. Extreme research efforts have been going on to develop new algal biotechnologies to get maximum productivity from microalgae. However, for full scale algae cultivation some issues like technical feasibility, environmental benefits from the culture, scaling up capability of the system still remain a big challenge [6] [7]. Though there are two culture systems are conventional: raceway pond and photo bioreactor [8] [9], none of those are yet to be proved so much fruitful for the optimization of the culture system. But photo bioreactor system is still reliable as it is free from the risk of contamination and requires less space.

Photo bioreactor technology can be used both in indoor and outdoor culture system. For full scale outdoor cultivation some environmental factors work as controlling parameters for the proper growth of microalgae. They are: fixed factors (location, geometry), variable factors (solar radiation variation, temperature, wind speed). The economics of the algal production depends largely on its occupied land area and exposure to sunlight. The amount of land area can be quantified by the sunlight reaching the ground in a definite locality and the fraction of light that is used in the photosynthesis of algae. To reduce the cost of land the factor is only limited with the sunlight. In case of full scale outdoor algae cultivation though chemical components, $\mathrm{P}^{\mathrm{H}}, \mathrm{CO}_{2}$ injection can be easily be controlled but controlling the broth temperature still remains a challenging task as it is directly associated with solar radiation. Temperature condition is still a very cru- 
cial factor as it has straightforward implications on the growth rate of microalgae. For the optimization of the design and the efficient operation of microalgae culturing devices, temperature plays a vital role and should be taken in account. In this context, a numerical model simultaneously showing temperature fluctuation and its impact on the productivity is a challenging task. Klametson et al. [10] in 1985 and Losordo et al. [11] in 1991 first described in their literature an empirical relationship between temperature fluctuation and growth rate of microalgae in case of waste water treatment, aquaculture ponds. But this was limited for a specific species. So a universal model is required to explain the temperature phenomena on the growth rate. Bechet et al. [12] at first proposed a universal temperature model including all kinds of parameters location, reactor geometry, sunlight irradiance. This model can precisely predict the evolving temperature of the culture growth medium in case of outdoor cultivation. Indeed, this model includes the direct and diffuse solar radiation but did not take into account if the weather is cloudy or not. The model describes a relationship between temperature variation and growth rate which is proposed by Bernard et al. [13] in his literature. This relationship works out for a full kinetic range of the microalgae culture including higher and lower temperature limit which reduce growth. Before that, Bissinger et al. [14] has developed temperature model but the temperature effect was presented by the simple exponential Arrhenius law which can only describe the impact of temperature on the rate of chemical reactions but cannot predict the negative impact of high and low temperatures.

Algae species can operate its photosynthetic process at the optimal temperature though some species endure beyond this temperature range. So to control the broth temperature it is necessary to develop a temperature model that is affected by the environmental parameters.

In this study, our aim is to develop a mathematical model of horizontal loop tubular photo bioreactor to simulate the temperature distribution in the suspension with the solar heat flux variation in a definite location and probable impact on the growth rate based on thermodynamic equilibrium. For the simulation, some relevant meteorological data are gathered for Chittagong, Bangladesh such as cloudiness, daily sunshine hours. For the broth medium we have considered the strain of Chlorella species.

\section{Mathematical Modeling}

In this simulation study, a dynamic heat management model is developed to predict the temperature distribution inside the horizontal loop tubular photo bioreactor (HLTP) as well as its effect on the growth rate of the microalgae. As temperature works as a controlling parameter behind the growth rate of microalgae so for this purpose, the solar radiation that reaches the photo bioreactor directly with varying solar position and heats up the microalgae cells is considered for our simulation. The data associated with the solar radiation are considered for the geographic location Chittagong University of Engineering \& 
Technology (CUET), Chittagong, Bangladesh.

\section{Computational Domain and Meshes}

A Horizontal Loop Tubular Photo bioreactor (HLTP) with a U-loop is proposed as the domain. Each straight portion is $10 \mathrm{~m}$ and the U-loop is approximately 0.5 $\mathrm{m}$. The radius of the photo bioreactor is $0.025 \mathrm{~m}$, the surface area is about 3.136 $\mathrm{m}^{2}$ and the volume is $0.03679 \mathrm{~m}^{3}$ as shown in Figure 1. A coarse mesh design is developed with 102,822 elements for the simulation. In Figure 2, the mesh design for the U-loop (a) and the inlet (b) are shown respectively.

\section{Governing Equation}

Algae suspension is considered as Newtonian incompressible fluid. For our simulation purpose the flow dynamics is assumed to be laminar. From this point of view, the flow phenomena satisfies the continuity equation and Navier Stokes equation which are as follows

$$
\begin{gathered}
\frac{\partial \rho}{\partial t}+\nabla \cdot(\rho \boldsymbol{u})=0 \\
\rho \frac{\partial \boldsymbol{u}}{\partial t}+\rho \boldsymbol{u} \cdot \nabla \boldsymbol{u}=-\nabla \rho+\nabla \cdot \mu\left(\left(\nabla \boldsymbol{u}+(\nabla \boldsymbol{u})^{T}\right)-\frac{2}{3} \mu(\nabla \cdot \boldsymbol{u}) I\right)+F
\end{gathered}
$$

Equation (2) can be solved for the Non isothermal laminar flow i.e. heat transfer in flowing fluid and can be written as

$$
\rho c_{p} \frac{\partial T}{\partial t}+\rho c_{p} \boldsymbol{u} \cdot \nabla T=\nabla \cdot(K \nabla T)
$$

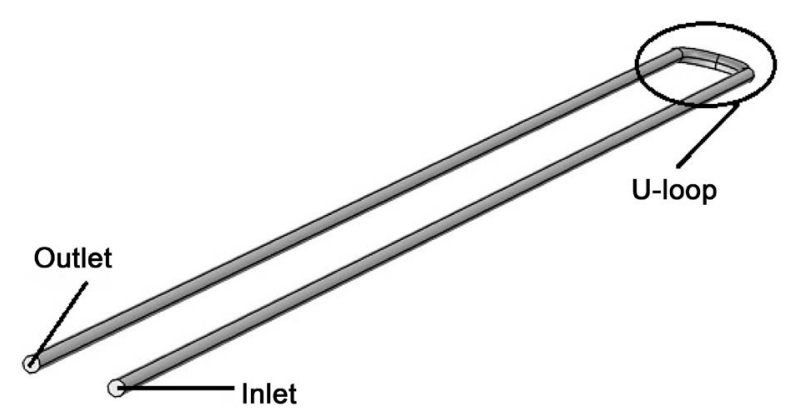

Figure 1. A computational domain of the HLTP showing inlet, outlet and U-loop.

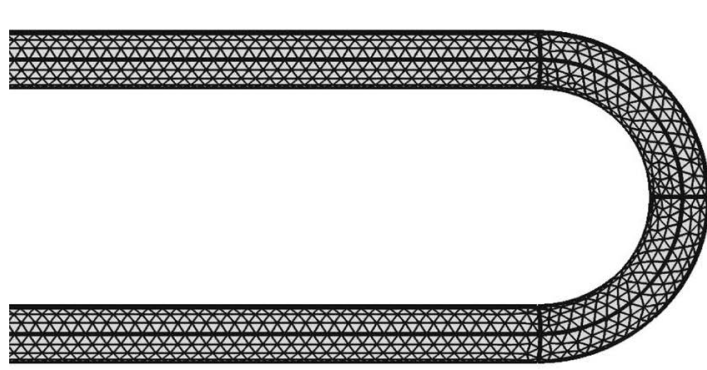

(a)

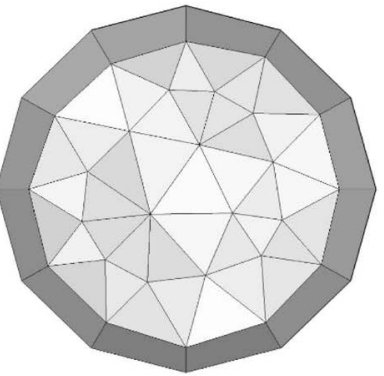

(b)

Figure 2. Coarse mesh design showing the (a) longitudinal view and (b) cross sectional view. 
where, $c_{p}$ is the specific heat of suspension, $T$ is the temperature, $K$ is the thermal conductivity.

As we know, radiation heat flux is directly negative proportional to $\nabla \cdot(K \nabla T)$, so a heat balance equation for the total direct solar radiation that reaches the photo bioreactor and heated up the microalgae cells can be expressed as

$$
\rho c_{p} \frac{\partial T}{\partial t}=Q_{\text {radiation(total) }}
$$

where, $Q_{\text {radt }}$ is the total solar heat flux from sun depending on the latitude of any geographical position in $\mathrm{W} / \mathrm{m}^{2}$.

The total heat flux comprises of the vertically and horizontally incident heat flux [15] shown in Equation (5)

$$
Q_{\text {radiation(total) }}=\left(Q_{\text {top }}+Q_{\text {lateral }}\right) f(t)
$$

where, $f(t)$ is considered as shading function. The value of $f(t)$ is set to 1 when there is available sunlight and set to 0 at night during outdoor cultivation of microalgae. The direct solar radiation that reaches the PBR vertically can be expressed by Equation (6)

$$
Q_{\text {top }}=\varepsilon_{\text {reactor }} \tau H_{d} \pi R_{r}^{2}
$$

where, $\varepsilon_{\text {reactor }}$ is the emissivity of the reactor, $\tau$ is the transmissivity of the reactor, $H_{d}$ is the intensity of the solar radiation reaching to the ground vertically.

The solar radiation received by the $\mathrm{PBR}$ laterally is given by

$$
Q_{\text {lateral }}=\varepsilon_{R} \tau H_{d} \tan (\theta) \pi R_{r}^{2}
$$

Generally, solar radiation reaches the ground surface in lateral position varies with the angular position $(\theta)$ of the incident sunlight. This angular position is a function of five parameters, they are: declination $(\delta)$, solar hour $(s h)$, geographic latitude $(\varphi)$, surface slope $(\beta)$, surface azimuth angle $(\tau)$ and the hour angle. The relation can be expressed by the Equation (8).

$$
\begin{aligned}
\cos \theta= & \sin \delta \sin \psi \cos \beta-\sin \delta \cos \psi \sin \beta \cos \tau \\
& +\cos \delta \cos \psi \sin \beta \cos \tau \cos \omega+\cos \delta \sin \beta \sin \tau \sin \omega
\end{aligned}
$$

Grima et al. [16] showed in his study that The PBR placed in horizontal position has an exposure to larger illumination area than any other position with respect to the variation in solar hour. For this reason, the surface slope $(\beta)$ is set to zero degree that provides the Equation (8) in its simplest form

$$
\cos \theta=\sin \delta \sin \psi+\cos \delta \cos \psi \cos \omega
$$

Duffie and Beckman [17] stated the solar declination angle $(\delta)$ as a function of number of days and the equation is as follows

$$
\delta=23.45 \sin \left[\frac{360}{365}(284+N)\right]
$$

The hour angle $(\omega)$ can be calculated from the following equation 


$$
\omega=15(s h-12)
$$

The hour angle $(\omega)$ varies from negative in the morning to positive in the afternoon with 15 degrees angular displacement per hour for the earth rotation from the east to the west.

In most of the cases, the direct solar radiation $\left(H_{d}\right)$ is a function of total solar radiation $(H)$ which comprises of diffuse plus direct solar radiation

$$
H_{d}=\left(1-K_{d}\right) H
$$

where, $K_{d}$ is the fraction of the diffused reaction reaching the ground surface. Typically its value ranges between 0.33 and 0.5 from low altitude areas to high altitude areas [18].

Almorox et al. established a relationship between the total solar radiation $(H)$ and the global solar radiation $\left(H_{0}\right)$ which is as follows

$$
\frac{H}{H_{0}}=a \cdot\left(\frac{s}{s_{0}}\right)^{b}
$$

In the above equation, $a$ and $b$ are regression coefficients that depend on the specific geographical location. As CUET is located in Chittagong, Bangladesh thus the values are taken for Chittagong, collected from the data from Sarkar [19].

Global solar radiation $\left(H_{0}\right)$ can be expressed as follows [17]

$$
\begin{aligned}
H_{0}= & \frac{\left(24 \times 3600 \times G_{s c}\right)}{\pi}\left(1+0.033 \cos \frac{360 N}{365}\right)(\cos \phi \cos \delta \sin \omega) \\
& +\frac{(\pi \omega)}{180} \sin \varphi \sin \delta
\end{aligned}
$$

The day length $\left(S_{0}\right)$ can be obtained from the following equation according to Duffie and Beckman [17].

$$
S_{0}=\frac{2}{15} \omega
$$

Rangarajan et al. [20] established a correlation between the total sunshine hours $(S)$ and the cloud fraction $(c)$ i.e. the monthly average daytime the sky is concealed with cloud

$$
c=1-\frac{s}{s_{0}}
$$

The term $c$ indicates the clearness index and the average value is taken for Chittagong from the data set in the paper of Sarkar [19].

The transmittance property of the photo bioreactor keeps a vital effect on the growth of microalgae cells as how much radiation is transmitted through the tube and reaches the microalgae cells to heat them up to maintain the broth temperature within the optimum range. Transmitted radiation can be determined from the product of transmittance of the reactor and the transmittance of the microalgae. 


$$
\tau=\tau_{T} * \tau_{A}
$$

where, $\tau_{T}$ is the reactor transmittance and can be evaluated from the following equation stated by Duffie and Beckman [17]

$$
\tau_{T}=0.5 *\left(\frac{1-R_{\text {parallel }}}{1+R_{\text {parallel }}}+\frac{1-R_{\text {perpendicular }}}{1+R_{\text {perpendicular }}}\right),
$$

where $R_{\text {parallel }}$ and $R_{\text {perpendicular }}$ are the parallel and perpendicular reflection from the tube and can be evaluated by the following equations

$$
\begin{gathered}
R_{\text {parallel }}=\left(\tan \left(\theta_{2}-\theta\right) * \pi / 180\right)^{2} /\left(\tan \left(\theta+\theta_{2}\right) * \pi / 180\right)^{2}, \\
R_{\text {perpendicular }}=\left(\sin \left(\theta_{2}-\theta\right) * \pi / 180\right)^{2} /\left(\sin \left(\theta+\theta_{2}\right) * \pi / 180\right)^{2},
\end{gathered}
$$

where $\theta_{2}$ is the angle after refraction from the transparent tube surface. It is a function of the angle of incidence of sunlight and the function of refraction index of air and the reactor.

$$
\sin \theta_{2}=\left(\frac{I R_{\mathrm{air}}}{I R_{\mathrm{reactor}}}\right) * \sin \theta
$$

Due to some associated losses the effective reflection of the tube is calculated as half of the perpendicular and parallel reflection of the tube

$$
R_{\text {effective }}=0.5 *\left(R_{\text {perpendicular }}+R_{\text {parallel }}\right) \text {. }
$$

The transmittance of the algae cells can be calculated using Bouger's law stated in Duffie and Beckman [17] which is given below

$$
\tau_{a}=\exp \left(-K_{a} * \frac{P L}{\cos \theta}\right)
$$

where, $K_{a}$ is the proportionally constant which the extinction coefficient of the microalgae cells. The value of $K_{a}$ is taken for the species Chlorella Vulgaris which varies with the variation of species. The total path length $P L$ is assumed to be the $60 \%$ of the total tube diameter [21].

To quantitatively account for the temperature distribution in the culture medium, a suitable model should be developed to predict the impact of the temperature fluctuation on the growth of microalgae culture.

Bernard et al. [13] expressed their model of the growth rate as a function of the maximum specific growth rate, maximum temperature, minimum temperature and optimum temperature. The model has named after cardinal temperature model with inflexion (CTMI).

$$
\mu_{m}=\mu_{\mathrm{opt}} \frac{\left(T-T_{\mathrm{max}}\right)\left(T-T_{\min }\right)^{2}}{\left(T_{\mathrm{opt}}-T_{\min }\right)\left[\left(T_{\mathrm{opt}}-T_{\min }\right)\left(T-T_{\mathrm{opt}}\right)-\left(T_{\mathrm{opt}}-T_{\max }\right)\left(T_{\mathrm{opt}}+T_{\min }-2 T\right)\right]}
$$

In the above equation, $T$ is the temperature in Kelvin or degrees Celsius $\left({ }^{\circ} \mathrm{C}\right)$, $\mu_{m}$ is the growth rate in minute ${ }^{-1}, \mu_{\mathrm{opt}}$ is the maximum specific growth rate at the temperature $T_{\mathrm{opt}}, T_{\max }$ and $T_{\min }$ is the hypothetical maximum and min- 
imum temperature limit. Growth rate is zero except the temperatures between $T_{\max }$ and $T_{\min }$. The maximum, minimum and optimum temperatures are called cardinal temperatures.

\section{Boundary and Initial Conditions}

In our simulation, the microalgae suspension flow is considered as a uniform flow and initially the velocity at the inlet is zero, i.e. $\boldsymbol{u}=0$; no slip condition at the wall of the reactor and zero normal stress at the outlet of the domain which can be written as

$$
\left[-P I+\eta(t)\left(\nabla \boldsymbol{u}+(\nabla \mathbf{u})^{\mathrm{T}}\right)\right] \boldsymbol{n}=0
$$

where, $P$ is the pressure and $I$ is the identity matrix.

\section{Simulation Parameters}

For the simulation, some of the simulation parameters are chosen specifically for the definite region i.e. Chittagong, Bangladesh. So the model does not apply for universal condition.

The simulation parameters are given in Table 1.

Table 1. Parameter used for simulation.

\begin{tabular}{|c|c|c|}
\hline Name & Value & Description \\
\hline$R$ & $0.025 \mathrm{~m}$ & Radius of the reactor \\
\hline$V$ & $0.03679 \mathrm{~m}^{3}$ & Volume of the reactor \\
\hline$A$ & $3.136 \mathrm{~m}^{2}$ & Area of the reactor \\
\hline$I R_{\text {air }}$ & 1 & Refraction index of air \\
\hline$I R_{\text {tube }}$ & 1.49 & Refraction index of acrylic tube \\
\hline$\phi$ & $22.46^{\circ}$ & Latitude of CUET \\
\hline$N$ & 75 & Day of the year \\
\hline$\varepsilon$ & 0.94 & Emissivity of the reactor \\
\hline$K_{a}$ & $36.9 \mathrm{~m}^{-1}$ & Extinction coefficient of Chlorella Vulgaris \\
\hline$\mu_{\max }$ & $0.0631 \mathrm{~h}^{-1}$ & Maximum growth rate of microalgae \\
\hline a & 1 & Constant value \\
\hline$b$ & 200 & Constant value \\
\hline$C_{0}$ & 0.55 & Initial concentration of microalgae \\
\hline$y_{w}$ & $0.001 \mathrm{~Pa} * \mathrm{~S}$ & Water viscosity \\
\hline$U_{\text {in }}$ & $0.5 \mathrm{~ms}^{-1}$ & Inlet initial velocity \\
\hline$G$ & $1367 \mathrm{w} / \mathrm{m}^{2}$ & Solar constant \\
\hline$P L$ & $0.03 \mathrm{~m}$ & Path length of the radiation \\
\hline$S$ & $8.1 \mathrm{~h}$ & Bright sunshine hour in the month of march \\
\hline$T_{\max }$ & $318[\mathrm{~K}]$ & Maximum temperature above which growth rate becomes zero \\
\hline$T_{\min }$ & $278[\mathrm{~K}]$ & Minimum temperature below which growth rate becomes zero \\
\hline$T_{\mathrm{opt}}$ & $300.5[\mathrm{~K}]$ & Optimum temperature at which the growth rate becomes maximum \\
\hline
\end{tabular}




\section{Numerical Simulation}

The aim of this study is to observe the temperature fluctuation in the photo bioreactor from dawn to dusk and consequently its effect on the growth of microalgae for specific geometry, specific species and specific location. All the parameters are considered here for the outdoor culture condition to observe the phenomena whether the temperature distribution is in the cardinal temperatures range or not. The COMSOL MULTIPHYSICS version 4.2a software is used to simulate the problem. The simulation is carried out for the seventh day of the microalgae culture and the photo bioreactor is assumed to be illuminated with varying solar radiation from morning to evening. The initial solution is kept at $\boldsymbol{u}=0$ for the whole domain except at the inlet. The simulation is carried out for three definite time ranges with definite time interval. The time ranges are: In the morning ( $6.00 \mathrm{am}$ to $6.15 \mathrm{am})$, the noon $(11.45 \mathrm{am}$ to $12.00 \mathrm{pm})$ and the afternoon $(3.00 \mathrm{pm}$ to $3.15 \mathrm{pm})$. For all cases, the time interval was $100 \mathrm{~s}$. For the geographical location, we have considered the latitude of CUET, Bangladesh. As in the Bangladesh the bright sunshine hour is in the month of March in the summer season so we have chosen the $16^{\text {th }}$ March for our simulation [22].

\section{Results and Discussions}

The simulation results are analyzed to observe the temperature distribution in three different times and temperature effects on a microalgae cell in the photo bioreactor. Also the most important factor growth curve against the temperatures collected from the simulation data is produced to gain knowledge on the productivity level of microalgae in this region. In Figure 3, surface temperatures are shown for three different times whereas in Figure 3(c) surface temperature reaches $325 \mathrm{~K}$ at $3.15 \mathrm{pm}$ which is beyond the upper cardinal temperature. In this situation the microalgae cell growth inhibits. In this case, water spraying system or shading system can be arranged to control the broth temperature.

In Figure 4, temperature slices of the suspension flow are presented in the morning, the noon and the afternoon. The slices are taken at the length of $5 \mathrm{~m}$, at the middle of the U-loop and at the length of $15.5 \mathrm{~m}$. In case of Figures 4(a)-(h) the temperature slice of the suspension shows the congenial environment for the growth of microalgae but in Figure 4(i), the temparature slice crosses the optimum range which is near the outlet of the domain at the afternoon. By observing Figure 4(b) \& Figure 4(e) \& Figure 4(h) and Figure 4(c) \& Figure 4(f) \& Figure 4(i) we have found that there is abrupt change of temperature from the middle portion of the u-loop to the outlet. This is due to the rapid mixing of the inner microalgae cells with the cells of the outer periphery while crossing the U-loop and thus receive more heat from the surface. Consequently, in Figure 4(c) \& Figure 4(f) \& Figure 4(i) the outer pheriphery shows higher temperature than the inner portion of the suspension.

In Figures 5(a)-(c) the temperature distributions against three different time ranges $(6.00 \mathrm{am}$ to $6.15 \mathrm{am}),(11.45 \mathrm{am}$ to $12.00 \mathrm{pm})$ and (3.00 $\mathrm{pm}$ to $3.15 \mathrm{pm})$ 


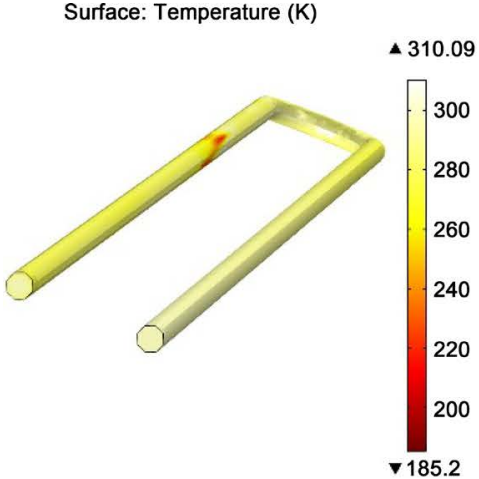

(a)

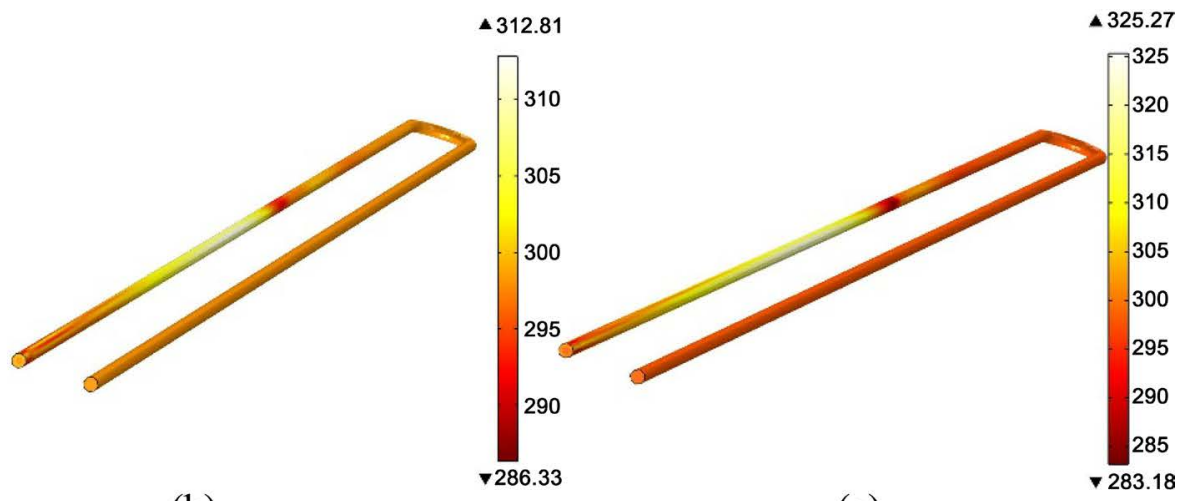

(b)

(c)

Figure 3. Surface temperature (a) at $6.15 \mathrm{am}$; (b) at $12.00 \mathrm{pm}$; (c) at $3.15 \mathrm{pm}$.

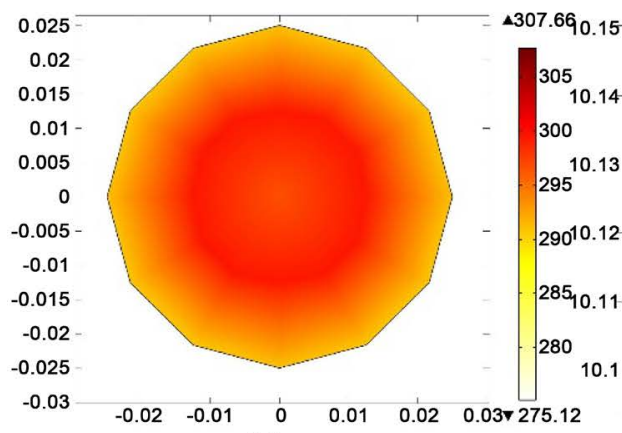

(a)

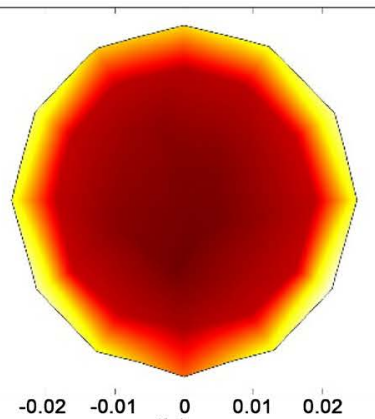

(b)

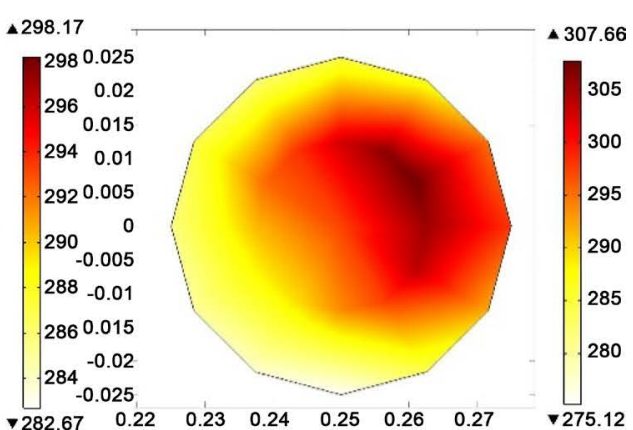

(c)

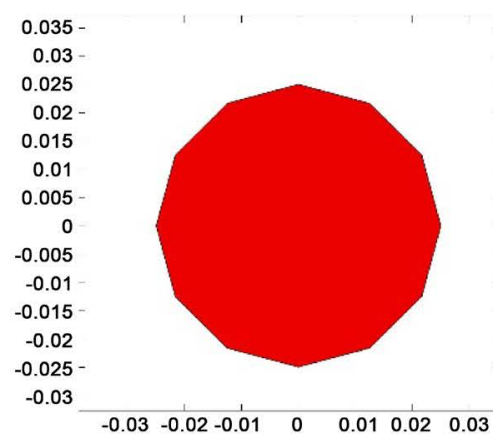

(d)

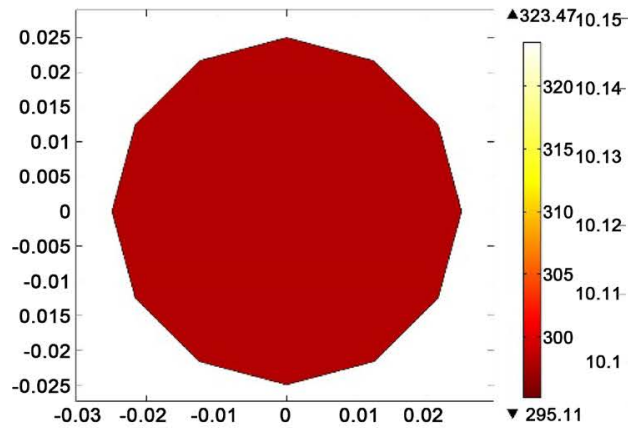

(g)
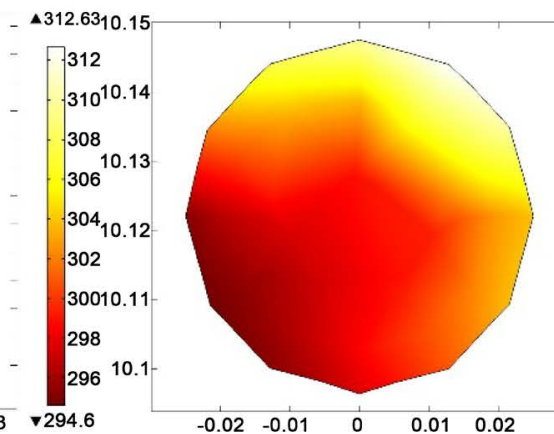

(e)

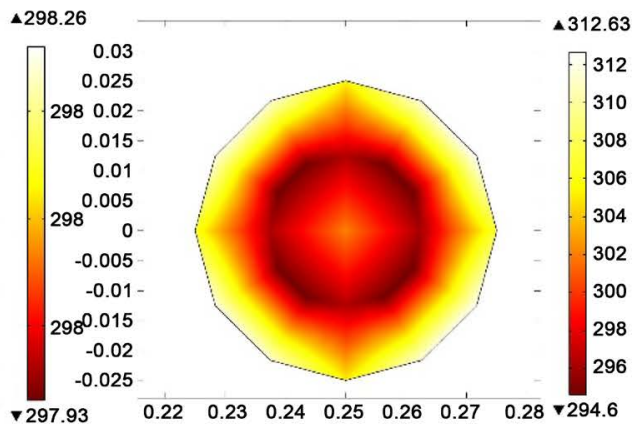

(f)

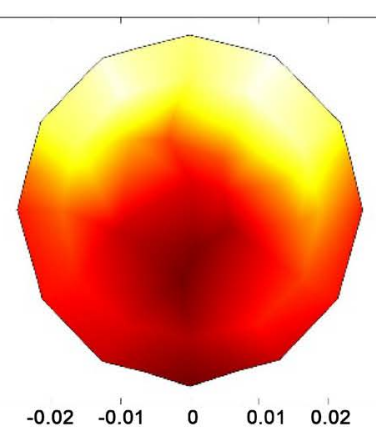

(h)

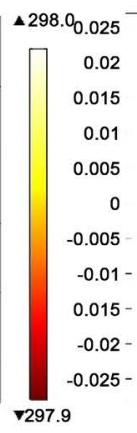

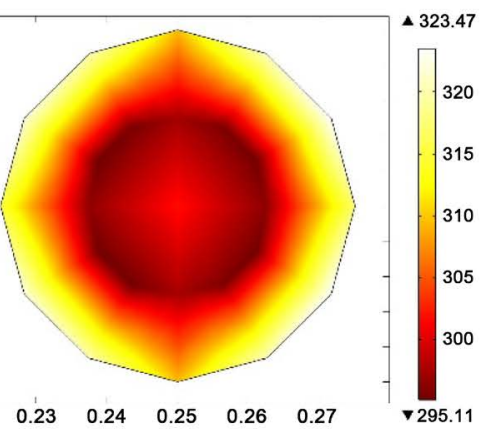

(i)

Figure 4. Temperature slice at $6.15 \mathrm{am}$ : arclength (a) $5 \mathrm{~m}$, (b) $10.25 \mathrm{~m}$, (c) $15.5 \mathrm{~m}$; at $12.00 \mathrm{pm}$ : arclength (d) $5 \mathrm{~m}$ (e) $10.25 \mathrm{~m}$ (f) $15.5 \mathrm{~m}$; at $3.15 \mathrm{pm}$ : arclength (g) $5 \mathrm{~m}$, (h) $10.25 \mathrm{~m}$, (i) $15.5 \mathrm{~m}$. 


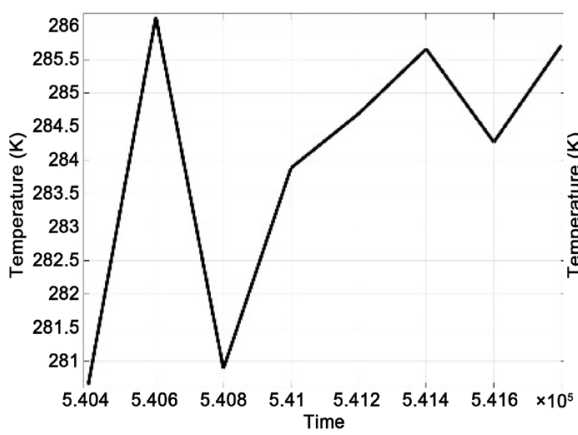

(a)

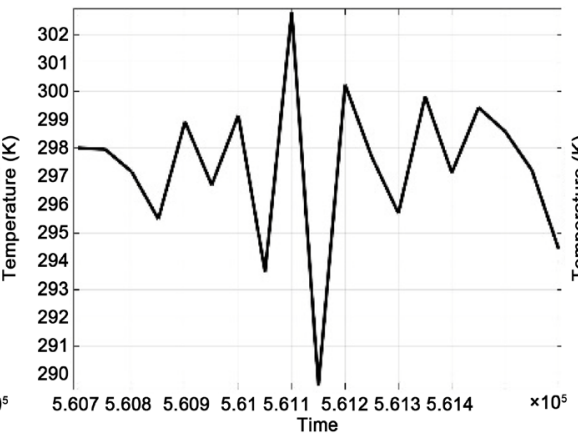

(b)

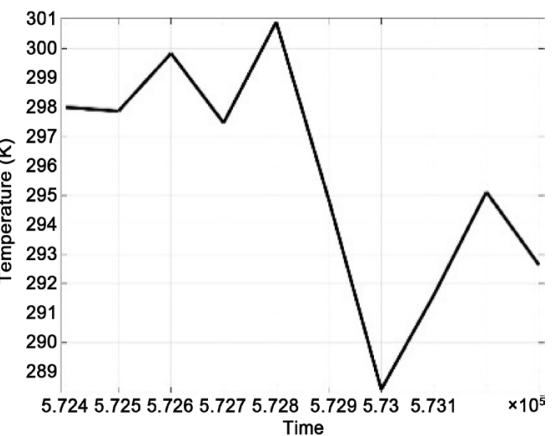

(c)

Figure 5. Temperature vs time for a mciroalgae cell at the outlet of the Photobioreactor (a) at 6 am -6.15 am; (b) at 11.45 am to $12.00 \mathrm{pm}$; (c) at $3.00 \mathrm{pm}$ to $3.15 \mathrm{pm}$.

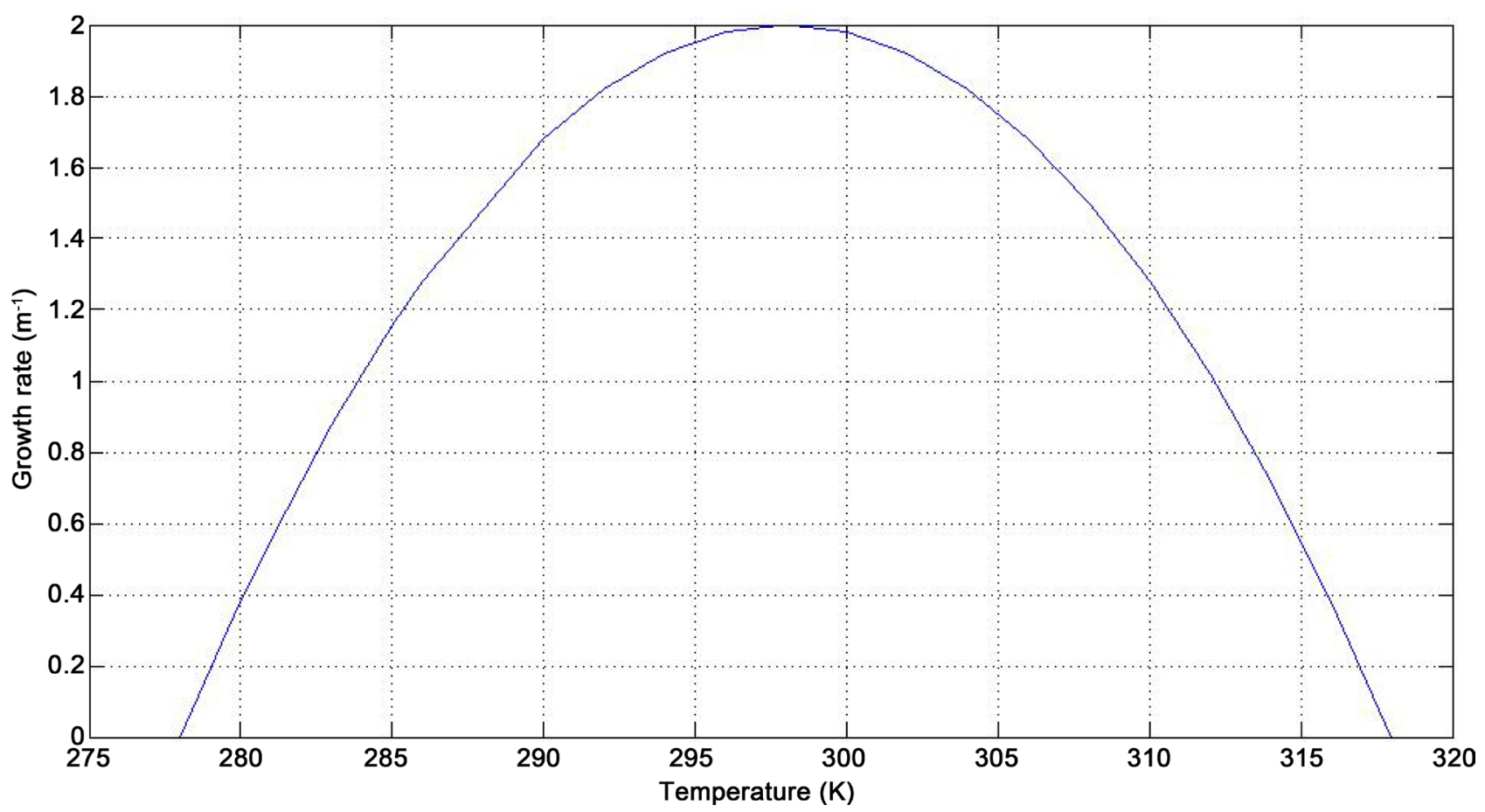

Figure 6. Temperatre vs growth rate $\left(\mathrm{m}^{-1}\right)$ (Temperatures collected from the simulation results).

are shown for a microalgae cell at the outlet. The cell is chosen from the lower position i.e. far from the upper surface to observe whether it receives the adequate temperature for its growth. In each case, we can see the temperature fluctuation lies between the cardinal temperatures.

As temperature fluctuation and its effect on the growth of the microalge is very crucial factor a growth curve against the temperatures collected from the simulation data is shown in the Figure 6. By using equation 24 the growth rate per minute is found. The graph shows a parabolic curve of growth rate vs temperature. From the Figure 6, it is shown that at the temperature $298 \mathrm{~K}$ the growth rate is maximum. At $278 \mathrm{~K}$ and at $318 \mathrm{~K}$ the growth rate becomes zero. It satisfies the cardinal temperatures of Chlorella Vulgaris as the Chlorella species can sustain between $5^{\circ} \mathrm{C}$ to $45^{\circ} \mathrm{C}$. Out of this range the cells start to demise. 


\section{Conclusions}

A CFD based study is performed to focus on the temperature variation on the growth rate of microalgae for a definite locality whether the place is suitable or not for the culture of microalgae. From the numerical results of the suspension flow it is conspicuous that the temperature always lies in the cardinal temperature range i.e., $5^{\circ} \mathrm{C}$ to $45^{\circ} \mathrm{C}$ most of the time through the entire domain except in the afternoon. At $3.00 \mathrm{pm}$ to $3.15 \mathrm{pm}$ the microalgae suspension temperature exceeds the threshold value for the optimum growth. So in this case temperature control of the culture broth should be maintained by applying proper engineering methods. Also it is an important fact to maintain the suspension the microalgae suspension temperature always close to the optimum temperature so that maximum growth can be ensured. Indeed, it is visualized by a symmetrical growth curve versus temperature. Beyond this optimum temperature, the decrease of the growth rate becomes linear and depending on the species reaches to the lethal temperature. The increasing rate of mortality with the temperature exceeds optimum value is a real fact but how much time these changes are experienced is an important issue to diagnose the extent of the mortality rate. The CFD model shows that temperature control techniques are necessary for the large scale production of microalge biofuel in this region to ensure the maximum productivity. The Combining of models on heat flux variation coupled with the effect of the temperature on the cell growth may lead to the temperature control strategies to achieve a tradeoff between the cooling cost and productivity. However, better outcome will be found if the simulation can be run for the daylong.

This paper is an extended version of our very recent paper [23] by putting more results and upgrade the growth model. In this paper the tempearature variation is observed in the broth culture of algae only for a single day perhaps the longest day hour. However, it is necessary to observe a full set of numerical data of temperature for the whole year to scale up and optimize the productivity. Recently Khanam et. al. [3] has given an average data of solar irradiance for 12 months of a year. So in the future, we would extend our work by applying the average irradiance for a month in a year as controlling parameter to observe the growth of microalgae cells for a large scale outdoor culture.

\section{Acknowledgements}

The authors gratefully acknowledge for the technical supports provided by the Centre of Excellence in Mathematics, Department of Mathematics, Mahidol University, Bangkok 10,400, Thailand and the Simulation Lab, Department of Mathematics, Chittagong University of Engineering \& Technology.

\section{References}

[1] Brennan, L. and Owende, P. (2009) Biofuels from Microalgae-A Review of Technologies for Production, Processing and Extractions of Biofuels and Co-Products, Renewable and Sustainable Energy Reviews, 14, 557-577. 
https://doi.org/10.1016/j.rser.2009.10.009

[2] Demirbas, A. (2007) Importance of Biodiesel as Transportation Fuel. Energy Policy, 35, 4661-4670. https://doi.org/10.1016/j.enpol.2007.04.003

[3] Khanam, I.A. and Deb, U.K. (2016) Calculation of the Average Irradiance and the Microalgae Groeth for a Year at CUET, Bangladesh. American Journal of Computational Mathematics, 6, 237-244. https://doi.org/10.4236/ajcm.2016.63024

[4] Chisty, Y. (2007) Biodiesel from Microalgae. Biotechnology Advances, 25, 294-306. https://doi.org/10.1016/j.biotechadv.2007.02.001

[5] Nigam, P.S. and Singh, A. (2011) Production of Liquid Biofuels from Renewable Resources. Progress of Energy \& Combustion Science, 37, 52-68. https://doi.org/10.1016/j.pecs.2010.01.003

[6] Lardon, L., Helias, A., Sialve, B., Steyer, J.-P. and Bernard, O. (2009) Life Cycle Assessment of Biodiesel Production from Microalgae. Environmental Science \& Technology, American Chemical Society, 43, 6475-6481. https://doi.org/10.1021/es900705j

[7] Walker, D.A. (2009) Biofuels, Facts, Fantasy and Feasibility. Journal of Applied Phycology, 21, 509-517. https://doi.org/10.1007/s10811-009-9446-5

[8] Deb, U.K., Chayantrakom, K. and Lenbury, Y. (2012), Comparison of Single-Phase and Two-Phase Flow Dynamics in the HLTP for Microalgae Culture. International Journal of Mathematics and Computers in Simulation, 6, 496-503.

[9] Tredici, M.R. (1999) Photo Bioreactors. In: Flickinger, M.C. and Drew, S.W., Eds., Encyclopedia of Bioprocess Technology: Fermentation, Biocatalysis and Bioseparation, Wiley \& Sons, New York, 395-419.

[10] Klemetson, S. and Rogers, G. (1985), Aquaculture Pond Temperature Modelling. Aquaculture Engineering, 4, 191-208. https://doi.org/10.1016/0144-8609(85)90013-5

[11] Losordo, T.M. and Piedrahita, R.H. (1991) Modelling Temperature Variation and Thermal Stratification in Shallow Aquaculture Ponds. Ecology Model, 54, 189-226.

[12] Bechet, Q., Shilton, A., Fringer, O.B., Munoz, R. and Guieysse, B. (2010) Universal Temperature Model for Shallow Algal Ponds Provides Improved Accuracy. Environmental Science \& Technology, 45, 3702-3709. https://doi.org/10.1021/es1040706

[13] Bernard, O. and Remond, B. (2012) Validation of a Simple Model Accounting for Light and Temperature Effect on Microalgal Growth. Bioresource Technology, 23, 520-527.

[14] Bissinger, J.E. and Montagnes, D.J.S. (2008) Predicting Marine Phytoplankton Maximum Growth Rates from the Temperature: Improving on the Eppley Curve using Quantile Regression. Limonology Oceanography, 53, 487-493. https://doi.org/10.4319/lo.2008.53.2.0487

[15] Bechet, Q., Shilton, A., Fringer, O.B., Munoz, R. and Guieysse, B. (2010) Mechanistic Modelling of Broth Temperature in Outdoor Photobioreactors. Environmental Science \& Technology, 44, 2197-2203.

[16] Camacho, F.G., Gomez, A.C., Fernandez, F.G.A., Sevilla, J.F. and Grima, E.M. (1999) Use of Concentric-Tube Airlift Photobioreactors for Microalgal Outdoor Mass Cutures. Enzyme and Microbial Technology, 24, 164-172.

[17] Duffie, J.A. and Beckman, W.A. (1980) Solar Radiation. In: Solar Engineering of Thermal Process, John Wiley and Sons, New York, 3-42.

[18] Almorox, J. and Hontoria, C. (2004) Global Solar Radiation Estimation using Sunshine Duration in Spain. Energy Conversion and Management, 45, 1529-1535. 
[19] Sarkar, N.I. (2016) Estimation of Solar Radiation from Cloud Cover Data of Bangladesh. Renewable: Wind, Water and Solar Springer Open, 3, 1-15.

[20] Rangarajan, S., Swaminathan, M. and Mani, A. (1984) Computation of Solar Radiation from Observation of Cloud Cover. Solar Energy, 32, 553-556.

[21] Mehlitz, T.H. (2009) Temperature Influence and Heat Management Requirements of Microalgae Cultivation in Photobioreactors. MSc Thesis.

[22] Islam, M.A., Alam, M.S., Sharker, K.K. and Nandi, S.K. (2016) Estimation of Solar Radiation on Horizontal and Tilted Surface over Bangladesh. Computational Water, Energy and Environmental Engineering, 5, 54-69.

[23] Shariar, M., Deb, U.K. and Rahman, K.A. (2017) Simulation of Temperature Effect on Microalgae Culture in a Tubular Photobioreactor for Local Solar Irradiance. AIP Conference Proceedings, 1851, Article ID: 020021.

Submit or recommend next manuscript to SCIRP and we will provide best service for you:

Accepting pre-submission inquiries through Email, Facebook, LinkedIn, Twitter, etc. A wide selection of journals (inclusive of 9 subjects, more than 200 journals)

Providing 24-hour high-quality service

User-friendly online submission system

Fair and swift peer-review system

Efficient typesetting and proofreading procedure

Display of the result of downloads and visits, as well as the number of cited articles

Maximum dissemination of your research work

Submit your manuscript at: http://papersubmission.scirp.org/

Or contact ajcm@scirp.org 